\title{
Results Obtained by Investigating Saffron Ussing FT-IR Spectroscopy
}

\author{
Luisa ANDRONIE ${ }^{1}$, Aurelia COROIAN ${ }^{*}$, Vioara MIRESAN ${ }^{1}$, Ioana POP ${ }^{2}$, Camelia RADUCU ${ }^{1}$, Ancuta \\ ROTARU $^{1}$, Loredana OLAR ${ }^{3}$ \\ ${ }^{1}$ Faculty of Animal Science and Biotechnologies, University of Agricultural Sciences and Veterinary \\ Medicine Cluj-Napoca, 3-5 Mănăștur Street, 400372, Cluj-Napoca, Romania \\ ${ }^{2}$ Faculty of Horticulture, University of Agricultural Sciences and Veterinary Medicine Cluj-Napoca, 3-5 \\ Mănăştur Street, 400372, Cluj-Napoca, Romania \\ ${ }^{3}$ Faculty of Veterinary Medicine, University of Agricultural Sciences and Veterinary Medicine Cluj- \\ Napoca, 3-5 Mănăștur Street, 400372, Cluj-Napoca, Romania \\ * corresponding author: coroian.aurelia@gmail.com
}

Bulletin UASVM Animal Science and Biotechnologies 73(2)/ 2016

Print ISSN 1843-5262; Electronic ISSN 1843-536X

DOI:10.15835/buasvmcn-asb: 12162

\begin{abstract}
Investigations of authentic and commercial saffron samples of different origin is very important. The biological activity and the pharmaceutical properties of plants are strongly dependent on their structure.The FT-IR spectra of saffron (commercial from India) have been obtained and the vibrational fundamentals from the IR spectrum, were analyzed and assigned acoording to the available literature.
\end{abstract}

Keywords: FT-IR (Fourier transform infrared) , Saffron (Crocus sativus)

\section{INTRODUCTION}

Saffron (Crocus sativus) belongs to the iris family is one of the highly prized spices known since antiquity for its color, flavor and medicinal properties.This contains several plant-derived chemical compounds that are known to have been anti-oxidant properties and it's a good source of minerals like copper, potassium, calcium, manganese, iron, selenium, zinc and magnesium.

This colorful spice has many non-volatile active component and the most important of them Alfa-crocin, a carotenoid compound, which gives the spice its characteristic golden-yellow hue, has been found to have anti-oxidant, anti-depressant, and anti-cancer properties.

Saffron extract has been shown to be capable of inhibiting or retarding the growth of tumors in a variety of experimental models in vivo. A topical application inhibited second-stage skin cancer, and oral administration of saffron extract restricted soft tissue sarcomas and inhibited tumor cell growth in mice (Fikrat, 2002). Because, the saffron is cultivated in many countries having very important medical properties is necessary experimental studies. Vibrational spectral techniques, FT- IR, offer several advantages in the context of current research and using this techniques we can identify molecular components in the samples studied. IR spectroscopy is based on the absorption of radiation in the $400-4000$ $\mathrm{cm}^{-1}$ range which excites molecular vibrations.

\section{AIMS AND OBJECTIVES}

Our research had the objective of analized a vibrational spectra of saffron commercially from India, using a method which is based on microscopic infrared study (FT-IR).

\section{MATERIALS AND METHODS}

The sample was obtained from $0,003 \mathrm{~g}$ of saffron commercially (filament samples). For FT-IR measurements were performed in the absorbance with a spectrophotometer FT-IR-4100 Jasco, using the $\mathrm{KBr}$ pellet technique.Spectral resolution was 


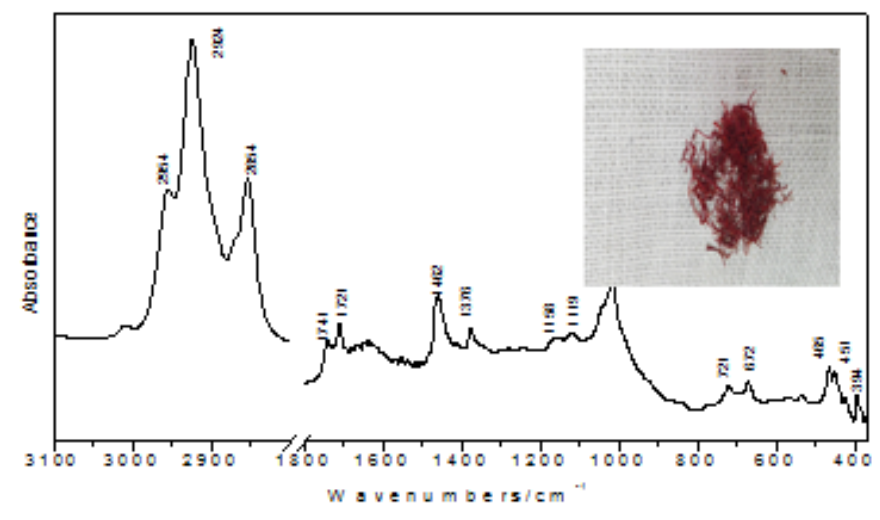

Fig. 1 FT-IR spectra of saffron commercially (filament sample) from India.

set at $4 \mathrm{~cm}-1$ and all spectra were acquired over 256 scans. The spectral data were analyzed using Origin 6.0 software.

\section{RESULTS AND DISCUSSION}

Cansonni et al., 2016, because the origin of saffton plants is important, make a study on authentic samples of saffron of known history (harvest and processing year, storage conditions, and length of time) some biomarkers were proposed using both FT-IR and NMR metabolomics regarding the shelf life of the product.

In other studies because this plants is a native of Southern Europe and today cultivated in many countries (Spain, Italy, France, Greece, Turkey, Iran, and in the India), Mid-infrared spectroscopy combined with multivariate analysis has been applied for the discrimination of 250 saffron samples from Greece (40 samples), Iran (87 samples), Italy (60 samples) and Spain (63 samples) (Anastasak et al. 2010).

The best discriminatory approach was achieved in the spectral region $2000-700 \mathrm{~cm}^{-1}$.The spectral region responsible for the differentiation of Italian samples is in the region of carbonyl group around $1746 \mathrm{~cm}^{-1}$. The spectral region at around $1600 \mathrm{~cm}^{-1}$ and the band at $1670 \mathrm{~cm}^{-1}$ are responsible for the differentiation of samples from the remaining countries. In the present work the infrared spectra of saffron filament samples (commercially of India) were recorded.

The vibrational FT-IR spectra (presented in Fig. 1) for commercial saffron were analyzed by comparing the experimental vibrational modes with the previous published data.

Making a comparasion between FT-IR specrum of saffron India and saffron of other countries, the peak at $1746 \mathrm{~cm}^{-1}$ attributed to the carbonyl grup, responsible for the differentiation of Italian samples, showed in previous studies (Anastasak et al., 2010), in this study is very weak and retrieved at $1741 \mathrm{~cm}^{-1}$. Another peak correspond to the carbonyl group appears at $1721 \mathrm{~cm}^{-1}$ in spectrum of saffrom from India.

The vibrational IR spectra of saffron is increased in relative intensity in the wavenumber range $2800-3000 \mathrm{~cm}^{-1}$. The very strong peaks at $2942 \mathrm{~cm}^{-1}$ and $2854 \mathrm{~cm}^{-1}$ corresponds to the $\mathrm{C}-\mathrm{H}$ stretching. The same attribution is available for the medium peak at $2964 \mathrm{~cm}^{-1}$.

The strong peaks at 1462 and $1081 \mathrm{~cm}^{-1}$, respectively correspond to the $\mathrm{C}=0$ stretching vibrations. Comparing our study whit previous studies the peack $1119,1376,2924$ and 2854 $\mathrm{cm}^{-1}$ is traced in FT-IR spectrum of saffron original from India.

\section{CONCLUSION}

Using vibrational spectroscopy, it was proven that we can identify key molecular components in the samples studied and their molecular structure.The major changes were observed in the spectral ranges where the carbonyl group exhibit characteristic vibrational modes.

\section{REFERENCES}

1. Atasaki E, Kanakis C, Pappas C (2010). Eur Food Res Technol, 230:571.

2. Consonni R, Ordoudi S, Cagliani L, Tsiangali M, Tsimidou M (2016). On the Traceability of Commercial Saffron Samples sing 1H-NMR and FT-IR Metabolomics. Molecules 21:286

3. Fikrat I (2002). Cancer Chemopreventive and Tumoricidal Properties of Saffron (Crocus sativus L.). Exp Biol Med (Maywood) 227 (1): 20-25. 